in the heat hydrolysis experiments, weighed amounts of leucine and leucylleucine, in separate flasks, were heated with water for 8 hours at i80$200^{\circ}$. On subsequent extraction with ether only a trace of anhydride was found in leucine while from leucyl-leucine more than $90 \%$ of the theoretical yield was obtained. From a control experiment with leucine anhydride heated under similar conditions practically the entire amount was recovered.

The above experiments would appear to eliminate the possibility of the building up of the anhydride from any leucine separated by the hydrolysis of protein. If, however, the dipeptide, leucyl-leucine, were among the cleavage products of the protein, it may readily be seen that this dipeptide would go over almost quantitatively to the anhydride. At the same time, there remains the possibility of the anhydride existing as such in the protein molecule as was indicated by Salaskin's experiments.

Since the heat hydrolysis method apparently gives results which may be interpreted either as measure of the leucyl-leucine or of the leucine anhydride content of the protein molecule, the amount of anhydride from several proteins has been determined quantitatively and the results seem worthy of note.

In each case $25 \mathrm{~g}$. of protein and $200 \mathrm{cc}$. of $\mathrm{H}_{2} \mathrm{O}$ were heated in an autoclave at $180-200^{\circ}$ for $I 6$ hours. The brown syrupy liquid which resulted was extracted with ether in a Soxhlet apparatus for 16 hours; the ether was then removed by distillation and the residue purified by repeated crystallizations from hot acetone up to the point at which a saturated solution of the anhydride was but slightly yellow. The purified substance formed from 15 to $20 \%$ of the crude ether extract. The crystals were finally dried at $100^{\circ}$ and weighed after cooling in a desiccator.

\begin{tabular}{|c|c|c|c|}
\hline Proteit. & Leucine antydride. & Protein. & Leucine anhydride \\
\hline Casein.. & $\ldots \quad 1.5 \%$ & Witte's peptone, & $\ldots \quad 1.0 \%$ \\
\hline Egg albumin & $1.2 \%$ & Silk......... & $0.09 \%$ \\
\hline Edestin... & I. $2 \%$ & Gelatin.... & $0.04 \%$ \\
\hline
\end{tabular}

NEW YORK, N. Y.

[Contribution from Chemistry Section of the Iowa Agricultural, Experiment StaTION.]

\title{
AN IODINE ADDITION PRODUCT OF CUMARIN.
}

By ARteur W. DOX and W. G. GakssLer.

Received October 25, 1916.

The recent work of Emery and Palkin ${ }^{1}$ on organic periodides is of especial interest to the writers in view of some experiments which we began two years ago on the reaction that takes place between Wagner's reagent and a solution of cumarin. Upon the addition of a few drops of an aqueous solution of iodine and potassium iodide to an aqueous solution of cumarin,

1 This Journat, 38, 2166 (I9I6). 
a precipitate forms, which is at first brown and flocculent, and then on shaking clots together to a dark green curdy mass, leaving a clear brown supernatant liquid. This is known as the "Leach test" for cumarin. With the exception of the mere mention of this test in Leach's textbook," practically nothing is to be found in the literature in regard to the chemistry of this reaction or the nature of the resulting product.

Under the conditions prescribed for the test, cumarin appears to have a remarkable affinity for iodine. The reaction is especially striking when the iodine reagent is applied with a glass rod to a few drops of the solution to be tested on a white plate or tile. Characteristic dark green flecks soon develop and gradually spread throughout the mixture, leaving a green scum at the surface. Upon spontaneous evaporation of the liquid and volatilization of excess free iodine, a mass of fine hair-like crystals remains, having a green iridescence and metallic luster. When dissolved in alcohol and evaporated again, the brilliant luster of the product becomes more apparent. The same effect is produced when the iodine reagent is added to an alcoholic solution of cumarin. Long, slender needles of greenish black luster, radiating from central points and forming starshaped bundles gradually separate out from the clear solution on standing overnight.

It was at first supposed that these crystals were a periodide of cumarin. A number of periodides, some of which resemble this substance in appearance and properties, have been described. All of them, however, as far as we can ascertain, have been prepared from nitrogenous substances with basic properties, such as alkaloids, purines, amides, and pyrazolons, and usually possess such formulas as $\mathrm{R}_{2} \mathrm{HII}_{2}, \mathrm{R}_{3}\left(\mathrm{HII}_{2}\right)_{2}$, etc. Iodide and iodine are present in definite proportions, and the latter readily reacts with thiosulfate.

In preparing the cumarin iodide the chief difficulty encountered was the purification of the product for analysis. Emery and Palkin ${ }^{2}$ wash their periodides with $60 \%$ alcohol previously saturated with iodine. Under this treatment, our product.rapidly goes into solution, even though the alcohol has been cooled in a refrigerator. Water decomposes the substance into cumarin and iodine. The usual organic solvents take up the cumarin and iodine, leaving a small residue of potassium iodide. When this residue is filtered off and the solvent allowed to evaporate, the cumarin, and iodine crystallize separately instead of yielding the original substance. The presence of potassium iodide appears to be necessary for maintaining the stability of the substance. In the absence of an iodide, the cumarin and iodine do not react, but tend to crystallize separately, and on treating the cumarin iodide with a solvent which leaves the iodide behind,

1 Leach, "Food Inspection and Analysis," 3rd Ed., p. 862.

Loc. cit. 
the original substance cannot be recovered. On the other hand, as will be shown presently, the iodide is present in the crystalline substance in so small an amount that it can hardly be reckoned into the formula.

Preparation I.-Cumarin, iodine and potassium iodide were used in the molectlar proportions of $2: 2: \mathrm{I}, \mathrm{I} .46 \mathrm{~g}$. cumarin and $\mathrm{r} .27 \mathrm{~g}$. iodine were dissolved in $30 \mathrm{cc}$. absolute alcohol with gentle warming, and $0.83 \mathrm{~g}$. potassium iodide in $20 \mathrm{cc}$. water added. In about an hour black needle-shaped crystals with the characteristic luster began to form. The mixture was then placed in an ice-box overnight. The crystals were then filtered off with suction and centrifuged. The yield was $0.635 \mathrm{~g}$. External iodine was determined by dissolving a weighed portion in a few cubic centimeters of alcohol, diluting with water, and titrating with standard thiosulfate. Total iodine was determined by dissolving the sample in ammonia, acidifying with sulfuric acid, adding ferric ammonium sulfate, and distilling the liberated iodine into a solution of potassium iodide surrounded by cracked ice. The iodine in the distillate was then titrated with thiosulfate. This method was tested with a known mixture of cumarin and potassium iodide and found to give quantitative results.

$$
\text { External iodine }=31.7 \% \quad \text { Total iodine }=33.3 \%
$$

Preparation II.-Cumarin, iodine and potassium iodide in molecular proportions of $\mathrm{I}: 2: 2.1 .46 \mathrm{~g}$, cumarin and $2.54 \mathrm{~g}$. iodine were dissolved as before and treated with $1.63 \mathrm{~g}$. potassium iodide, and placed in the ice-box for the same length of time. The yield in this case was $\mathrm{I} .32 \mathrm{~g}$.

$$
\text { External iodine }=31.7 \% \quad \text { Total iodine }=33.3 \%
$$

Preparation III.-r.46 g. cumarin, I.27 g. iodine in $20 \mathrm{cc}$. absolute alcohol, and $0.83 \mathrm{~g}$. potassium iodide in $20 \mathrm{cc}$. water.

$$
\text { External iodine }=30.5 \% \quad \text { Total iodine }=30.5 \%
$$

Preparation IV. $-7.3 \mathrm{~g}$. cumarin, $6.35 \mathrm{~g}$. iodine in Ioo $\mathrm{cc}$, alcohol, and 4. 15 potassium iodide in roo cc. water. The product was recrystallized from $50 \%$ alcohol containing iodine and potassium iodide.

$$
\text { External iodine }=3 \mathrm{r} .5 \% \quad \text { Total iodine }=33.0 \%
$$

In order to determine whether substitution of iodine occurs in the cumarin molecule as it does in the case of antipyrine, yielding an iodo derivative, a portion of Preparation II, above, was dissolved in chloroform and shaken in a separatory funnel with a very slight excess of thiosulfate solution. The color of the iodine quickly disappeared, and the chloroform on evaporation gave the characteristic crystals of cumarin, melting at $67^{\circ}$. When mixed with cumarin of known purity the melting point of these crystals did not change. Substitution, therefore, does not occur, and, the method described above for determining total iodine is applicable. 
All of the above preparations melted at $88^{\circ}$. The substance is quite stable in the air at room temperature, but loses iodine when warmed, and more gradually when spread out in the air, at the same time becoming lighter in color. In a stoppered bottle it remains unchanged indefinitely. It is very soluble in most organic solvents, the iodine giving the.brown or violet color characteristic for the solvent.

Three out of four of the preparations showed an excess of total over external iodine as will be seen from the analyses. The difference represents iodine in the form of iodide. The iodine in this form is, however, a very small fraction of the total, and a periodide formula would require high multiples of cumarin and external iodine. Considering the fact that the crystals could not be purified by washing, it is probable that some iodide from the mother liquor remains as an impurity. Such admixture of iodide would tend to retain also an excess of external iodine. This may account for the variations in the iodine determinations on the different samples. Moreover, in one preparation, the figures for external and total iodine are identical. The simplest formula for an iodide of cumarin with an iodine content approaching these results is $\left(\mathrm{C}_{9} \mathrm{H}_{6} \mathrm{O}_{2}\right)_{2} \mathrm{I}$, or more probably $\left(\mathrm{C}_{9} \mathrm{H}_{6} \mathrm{O}_{2}\right)_{4} \mathrm{I}_{2}$, where the calculated value is $30.5 \%$.

When sodium chloride was substituted for potassium iodide in the preparation of the substance, the cumarin and iodine crystallized separately. When, however, potassium bromide was used, black crystals with a violet luster were obtained. These had an external iodine content of $31.7 \%$.

AMES, IOWA.

[CONTRIBUTION FROM THE ChEMICAL LABORATORY OF WESLEYAN UNIVERSITY.]

\section{RESEARCHES ON THE ACTION OF SULFURIC ACID ON CER- TAIN NITROCARBOCYCLIC COMPOUNDS. I. THE ACTION ON NITROBENZENE.}

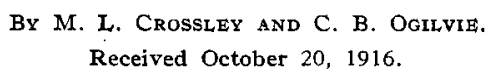

Introduction.

As a result of an attempt to condense $\beta$-aminoanthraquinone and certain dicarboxylic acids of the acyclic series, in the presence of nitrobenzene, by means of sulfuric acid, we find that, at a temperature of about $175^{\circ}$, a vigorous reaction takes place, with the production of a purplish black product which, at first glance, appears to be chiefly carbon. Investigation proves that concentrated sulfuric acid dissolves it, forming a dark greenish blue solution. The product is reduced by alkaline hydrosulfite to a brown solution which produces a fast heliotrope color on cotton. The reaction appears to be quite general for nitrocarbocyclic compounds and is not influenced by the acyclic acid. In every case this is recovered 